\title{
PROCESSOS FORMATIVOS A PARTIR DE PRÁTICAS INCLUSIVAS NA EDUCAÇÃO BÁSICA*
}

\author{
Gilberto Ferreira da Silva, \\ do Centro Universitário La Salle, Canoas \\ MARTA NÖRNBERG, \\ do Centro Universitário La Salle, Canoas \\ Suzana Moreira Pacheco, \\ do Centro Universitário La Salle, Canoas
}

Resumo: Este artigo resulta de uma experiência de pesquisa, com características colaborativas, desenvolvida com um grupo de professores de quatro escolas da rede municipal de ensino de Porto Alegre. Nele, analisamos a gênese do processo de pesquisa estabelecido entre Universidade e Escola e o desenvolvimento dos encontros de formação e de escrita colaborativa. A partir dos aportes teórico-metodológicos da pesquisa-ação, sistematizamos e analisamos o processo de formação continuada e de escrita colaborativa. Da análise dos registros escritos pelas professoras é possível afirmar três aspectos que possuem um caráter inovador das formas de pensar e fazer a docência na Educação Básica: a) a prática da Inclusão desde a experiência cotidiana da docência compartilhada; b) a formação de professores desde a dimensão da pesquisa e da autoria escrita; c) a compreensão de Docência Compartilhada e de trabalho coletivo na escola como indicadores de inovação educativa. Por fim, sustentamos que o movimento de formação continuada, quando realizado em rede, possibilita a melhoria da prática pedagógica e a qualificação dos processos de inclusão educativa.

Palavras-chave: Formação de professores. Educação inclusiva. Pesquisa-ação. Docência compartilhada. Escrita colaborativa.

\footnotetext{
* Artigo recebido em 16/10/2009 e aprovado em 16/12/2011.
} 
INTRODUÇÃO

Vive-se um tempo no campo da educação em que proliferam iniciativas inovadoras que convivem com ações clássicas e convencionais do fazer educativo. Cada vez mais a construção de alternativas inovadoras no campo das ações pedagógicas cotidianas tem sido um elemento presente nas narrativas de professores em espaços de socialização e de formação continuada, principalmente quando relacionada aos processos de inclusão educativa e social. Nesse cenário, emergem discussões que recolocam em pauta antigas questões, atualizando-as, ou, simplesmente, traduzindo-as em um discurso contemporâneo sem que, efetivamente, tais inovações e mudanças sejam sinônimas de transformações.

Este texto situa-se no limiar das fronteiras do que se tem convencionado denominar inovações, mudanças e transformações educativas. Fronteiras que exigem considerar que as inovações, as mudanças e as transformações são realizáveis quando se assume o caráter histórico da escola, reconhecendo-a como criação humana, portanto, contingente e suscetível de assumir várias formas organizacionais. Ou seja, "é justamente na medida em que constitui uma 'invenção' que se torna possível pensar a possibilidade de sua reinvenção" (CANÁRIO, 2006, p. 85). O pesquisador Rui Canário pontua que muitas das tentativas de mudar a escola têm sido marcadas pela realização de reformas conduzidas de "cima para baixo" ou importando para o contexto escolar um modelo industrial de produção de inovações (2006, p. 91). Tais tentativas, consequentemente, inviabilizam ou enfraquecem os processos de gestão democrática e o próprio exercício democrático. Como alternativa, o autor sugere a generalização de estratégias indutivas de mudança construídas com os professores, colocando as escolas como lugares onde se produzem práticas profissionais e onde se produzem conhecimentos sobre tais práticas profissionais.

A construção da autonomia profissional dos professores é uma condição para superar a crise de identidade que os afeta e para que se possa aproveitar o potencial de criatividade que habita as escolas e o patrimônio de experiências inovadoras do local, com as quais o sistema escolar tem se revelado incapaz de aprender. (CANÁRIO, 2006, p. 92)

Tecido com mãos que se preocupam com os rumos da educação nos tempos atuais, este texto não é simplesmente a organização de fragmentos do cotidiano escolar. Trata-se do resultado de uma experiência de pesquisa, com características colaborativas, ${ }^{1}$ desenvolvida com um grupo de professores de escolas que realizam mudanças político-pedagógicas voltadas para a 
inclusão educativa, na rede municipal de ensino de Porto Alegre. A seguir, apresentamos a gênese do processo de pesquisa e o desenvolvimento dos encontros de formação e de escrita colaborativa.

\section{SOBRE O PRINCÍPIO DA PROPOSTA DE PESQUISA}

A busca por alternativas inovadoras no campo das ações pedagógicas cotidianas tem sido um dos elementos presentes nas narrativas de professores em espaços de socialização, confraternização e formação educativa, principalmente quando relacionadas aos processos de inclusão educativa e social.

No final de 2007, um grupo de escolas levou à secretaria de educação da rede municipal de Porto Alegre uma demanda que propunha reorganizar os espaços educativos, repensar a docência e, acima de tudo, construir alternativas para dar conta dos processos de inclusão de estudantes com deficiência e/ou com dificuldades de aprendizagem. Os representantes das escolas não estavam apresentando meramente uma solicitação para dar início a algum tipo de trabalho ou projeto educativo. Na verdade, o grupo apresentava uma solicitação para qualificar as experiências que vinham realizando na tentativa de construir propostas de adequação curricular e pedagógica. O denominador comum entre essas escolas, em maior ou menor grau, diz respeito à experiência vanguardista iniciada na Escola Municipal Gilberto Jorge e, mais tarde, reconstruída por outras três escolas, que também vinham produzindo algum tipo de adaptação curricular.

Em função da experiência de construção de alternativas de adaptação curricular e de práticas compartilhadas de docência realizadas na Escola Gilberto Jorge, tomada como inspiração para as demais escolas, optou-se por denominar, no âmbito da secretaria municipal de educação, o movimento realizado pelos professores nessas quatro escolas com o mesmo nome utilizado na Gilberto Jorge, qual seja, projeto "Docência Compartilhada". Conforme informam Pacheco e Monteiro (2007), o projeto Docência Compartilhada objetiva "avançar em relação ao tratamento das diferenças, primando pelo respeito ao direito à diferença, visando à aprendizagem de todos, no sentido mais amplo e complexo do termo" (p. 2).

A secretaria de educação do município, propondo-se a atender essa demanda, assumiu o lugar de mediadora entre os representantes das quatro escolas e procurou por pesquisadores do ensino superior que pudessem assessorar, acompanhar e potencializar o trabalho, objetivando articular a colaboração entre universidade e escola. Como objetivo central, estabeleceuse o investimento na formação dos professores envolvidos no trabalho das 
quatro escolas e na criação de uma metodologia de trabalho que favorecesse a escrita colaborativa, com vistas à sistematização das experiências, e a produção de conhecimentos teórico-práticos sobre a docência compartilhada.

Como pesquisadores da universidade, assumimos o trabalho conscientes de que ele extrapolaria as práticas convencionais de pesquisa que estávamos acostumados a realizar. Damo-nos conta, desde o princípio, de que ocuparíamos um lugar em que cumplicidade e colaboração seriam elementos fundamentais para o andamento e a execução dos objetivos propostos pelos educadores envolvidos na proposta.

O desafio de vivenciar uma pesquisa com características diferenciadas das práticas investigativas convencionais, nas quais, em raras ocasiões, os professores da educação básica não ultrapassam a função de meros cedentes de dados para análises acadêmicas, vem, há algum tempo, nos preocupando e fazendo com que busquemos outros referenciais para se pensar os processos formativos de educadores. Nesse sentido, algumas experiências já realizadas por nós têm apontando o quanto o trabalho de parceria entre universidade e escola pode ser vantajoso para ambos (SILVA, SOUZA, 2006; PERSCH, PACHECO, MONTEIRO, 2006).

Os estudos de Zeichner e Diniz Pereira (2005), Tardif e Raymond (2000), Grigoli, Josefa A. G. et. al. (2007), Pimenta (2005) enfatizam o quanto o trabalho de colaboração entre Universidade e Escola permite revisar as ações e as práticas pedagógicas dos educadores de forma mais eficiente. Assim, com Pimenta (2005), podemos afirmar que

[...] a pesquisa partia de uma aposta: a da possibilidade e necessidade ética da articulação emancipatória entre pesquisador e sujeitos pesquisados, conferindo à atividade científica um compromisso com a fertilização de teorias e ações que subsidiassem a práxis dos professores, no sentido da transformação das condições de ensino e de aprendizagem, por meio da transformação de sentido que passariam a conferir às práticas institucionais. (p. 528)

Após acordos preliminares, entre órgão público de ensino, pesquisadores e representantes das escolas, construiu-se um pré-projeto de pesquisa que pudesse, num primeiro momento, orientar o andamento dos trabalhos. ${ }^{2}$ Definiu-se um conjunto de objetivos que, naquele momento, de alguma maneira, representavam as aspirações do grupo de pesquisadores: ${ }^{3}$

1) Caracterizar os projetos diferenciados de cada uma das quatro escolas, quanto à forma de articulação da docência, do conceito de aprendizagem e da concepção de diferença. 
2) Promover espaços de diálogo entre as escolas, procurando reconhecer o potencial de cada uma das experiências, identificando pontos convergentes e divergentes nas diferentes propostas.

3) Constituir ambientes de formação em serviço, instrumentalizando o grupo, naquilo que vem sendo percebido como falta na operacionalização dessas propostas diferenciadas.

4) Garantir a autoria de todos os envolvidos na gestão e operacionalização dos projetos diferenciados, incentivando o registro e a divulgação do trabaIho nas diferentes perspectivas de sua implementação.

5) Interagir com as equipes da SMED envolvidas com as políticas de inclusão/ diversidade, fomentando sua participação nos diálogos com o grupo das quatro escolas em questão.

6) Desenvolver estratégias que permitam dar voz aos alunos, pais e/ou responsáveis envolvidos direta ou indiretamente, nos projetos diferenciados.

7) Avaliar o trabalho que vem sendo desenvolvido no grupo das quatro escolas, procurando evidências de seu potencial inclusivo, verificando possibilidades futuras de adaptação de seus princípios na constituição de novas políticas públicas. (PACHECO, 2008, p. 1-2)

Uma vez construídos os objetivos do projeto de pesquisa e configurada a equipe de pesquisadores universitários, estabelecemos algumas estratégias de comunicação com o conjunto dos professores das quatro escolas envolvidas. Entre elas, definiu-se, com o apoio da secretaria de educação, a liberação de um professor que pudesse coordenar o processo dentro da rede municipal de ensino, mantendo contato constante com os professores, principalmente fomentando o processo de escrita colaborativa. Acertou-se também que os mesmos professores integrantes da equipe de pesquisa atuariam nas atividades de formação continuada a fim de potencializar o processo de escrita colaborativa.

O trabalho de pesquisa envolveu três atividades centrais:

a) Encontros formativos para estudo e discussão de aspectos teóricometodológicos dos temas propostos pelos professores sobre os quais eles escreveriam posteriormente de forma colaborativa em cada uma das escolas envolvidas;

b) Sistematização da experiência em cada uma das escolas, mediante a escrita colaborativa de artigos e relatos de experiência;

c) Produção de um DVD com registros e depoimentos das práticas cotidianas de adaptação curricular e gestão dos processos de ensinoaprendizagem na perspectiva da docência compartilhada. 
Inicialmente, os encontros formativos foram agendados com todos os professores-pesquisadores, objetivando ampliar a compreensão sobre os aspectos teórico-metodológicos que envolviam o cotidiano da experiência posta para análise. Foram definidos quatro encontros formativos, cada um tendo um "professor-pesquisador" da Universidade convidado para estimular o debate e tendo como princípio orientador a ideia de que o diálogo deveria ser um componente inerente a todos os encontros. Concomitantemente com essa atividade, estabelecemos duas tarefas a serem realizadas em cada uma das escolas. A primeira delas consistia no exercício da reflexão e do registro da experiência feita por meio da produção de um texto. Na escrita do texto os professores deveriam sistematizar aspectos que caracterizavam a experiência e indicar os elementos teóricos que a sustentavam ou auxiliavam a tensionar o processo de inclusão desencadeado no interior de cada unidade educativa em que atuam. ${ }^{4}$ Ao longo dos encontros de formação, os textos foram sendo escritos, lidos e problematizados pelo grupo de pesquisadores; foi um tempo de rever, retomar, ampliar, qualificar o processo de reflexão e de produção escrita.

A segunda tarefa foi a produção de um DVD em que se recolheram recortes imagéticos e narrativas das experiências em andamento em cada uma das escolas. Para isso, cada escola, com seu grupo de professores, fez uma seleção das práticas e depoimentos que comporiam o DVD final. A partir dessa seleção, alunos, pais e professores gravaram seus depoimentos assim como cenas do cotidiano da sala de aula foram gravados. Por fim, a equipe de pesquisadores realizou a edição do material.

Na sequência deste texto, explicitamos as bases metodológicas que nos permitiram sistematizar e analisar o processo de pesquisa realizado. Apresentamos, também, algumas reflexões extraídas dos registros das professoras e a decorrente análise feita com base na literatura corrente sobre os processos de organização e gestão de programas e práticas pedagógicas inclusivas.

\section{AS BASES TEÓRICO-METODOLÓGICAS DO CAMINHO FEITO}

Não pretendemos fazer a defesa de um pressuposto teóricometodológico definido a priori. O que propomos é reconstruir os passos que conduziram a pesquisa, procurando, nessa sistematização, a posteriori, aprender com a trajetória realizada. Conforme já dito, o objetivo da pesquisa carregou desde o princípio características do que podemos nominar de pesquisa colaborativa. Essa estratégia de investigação insere-se no escopo de uma tradição já consolidada e conhecida como pesquisa-ação. 
Em seu elucidativo artigo sobre as diferentes abordagens comumente empregadas para designar a pesquisa-ação, Maria Amélia Santoro Franco (2005) sintetiza três conceituações:

a) quando a busca de transformação é solicitada pelo grupo de referência à equipe de pesquisadores, a pesquisa tem sido conceituada como pesquisa-ação colaborativa, em que a função do pesquisador será a de fazer parte e cientificizar um processo de mudança anteriormente desencadeado pelos sujeitos do grupo;

b) se essa transformação é percebida como necessária a partir dos trabalhos iniciais do pesquisador com o grupo, decorrente de um processo que valoriza a construção cognitiva da experiência, sustentada por reflexão crítica coletiva, com vistas à emancipação dos sujeitos e das condições que o coletivo considera opressivas, essa pesquisa vai assumindo o caráter de criticidade e, então, tem se utilizado a conceituação de pesquisa-ação crítica;

c) se, ao contrário, a transformação é previamente planejada, sem a participação dos sujeitos, e apenas o pesquisador acompanhará os efeitos e avaliará os resultados de sua aplicação, essa pesquisa perde o qualificativo de pesquisa-ação crítica, podendo ser denominada de pesquisa-ação estratégica. (p. 485-486)

O debate instaurado, desde meados do século passado, sobre as contribuições da pesquisa-ação para a produção do conhecimento científico tem, paulatinamente, ganhado espaço. Observam-se nas últimas duas décadas uma proliferação da discussão veiculada por periódicos acadêmicos em que se apresentam de diferentes formas e abordagens as contribuições desse tipo de pesquisa para a construção do conhecimento, destacando, substancialmente, a melhoria continuada, sistemática e empiricamente fundamentada para aprimorar a prática (PAULON, 2005; FRANCO, 2005; ENGEL, 2000; MIRANDA e RESENDE, 2006; MONCEAU, 2005; ZEICHNER e DINIZ-PEREIRA, 2005; ABDALLA, 2004).

Zeichner e Diniz-Pereira (2005) são enfáticos ao afirmar o quanto a pesquisa-ação contribui para a formação de profissionais da educação tendo em vista a transformação social de uma prática. Destacam quatro maneiras de como isso pode ocorrer:

1. melhorar a formação profissional e, por conseguinte, propiciar serviços sociais (educação, saúde etc.) de melhor qualidade; 2 . potencializar o controle que esses profissionais passam a exercer sobre o conhecimento ou a teoria que orienta os seus trabalhos; 3 . influenciar as mudanças institucionais nos locais de trabalho desses profissionais (escolas, hospitais, agências de serviço social etc.); 4. contribuir para que as sociedades tornem-se mais democráticas 
e mais decentes para todos (ou seja, sua ligação com temas de reprodução ou de transformação social). (p. 64-65)

Finalmente, trazemos alguns princípios fundantes da pesquisa-ação, seguindo as proposições de Franco (2005). Diz a autora que a pesquisa-ação, no campo educativo, deve contemplar:

- a ação conjunta entre pesquisador-pesquisados;

- a realização da pesquisa em ambientes onde acontecem as próprias práticas;

- organização de condições de autoformação e emancipação dos sujeitos da ação;

- a criação de compromissos com a formação e o desenvolvimento de procedimentos crítico-reflexivos sobre a realidade;

- o desenvolvimento de uma dinâmica coletiva que permita o estabelecimento de referências contínuas e evolutivas com o coletivo, no sentido de apreensão dos significados construídos e em construção;

- reflexões que atuem na perspectiva de superação das condições de opressão, alienação e de massacre da rotina;

- ressignificações coletivas das compreensões do grupo, articuladas com as condições sócio-históricas;

- o desenvolvimento cultural dos sujeitos da ação. (p. 489)

Diante do exposto, encontramos ressonância para o que realizamos nesta pesquisa no modelo que a autora denomina de pesquisa-ação colaborativa. Vivemos um processo em que a configuração do problema constituiu-se num movimento de dentro para fora, ou seja, originou-se a partir de uma experiência em andamento, levado a efeito por um coletivo de professores da educação básica que, retroalimentados por espaços de socialização de práticas de docência, deram-se conta do vitalismo de suas ações e buscaram formas de fortalecê-las e promovê-las a fim de multiplicálas, criando uma espécie de rede estratégica não intencional. Esse movimento, em primeiro lugar, acabou gerando uma busca coletiva por melhores formas de compreender e atuar em torno de um problema comum, o desafio da inclusão. Em segundo lugar, promoveu a construção de alternativas para os processos de revigoramento e ampliação da capacidade de criação coletiva, mediante a reflexão e a escrita colaborativa.

Nesse caso específico, a busca de transformação foi solicitada pelo grupo de professores que protagonizaram o Projeto Docência Compartilhada, na Escola Gilberto Jorge, e por professores de outras escolas que, através de processos de intercâmbio em espaços rotineiros de formação na Rede 
Municipal de Ensino, aderiram ao movimento dos professores da Gilberto Jorge. De forma colaborativa, os professores, em suas escolas de origem, iniciaram o movimento de reconstrução da proposta pedagógica de forma adaptada aos seus contextos educativos. $O$ olhar atento ao movimento realizado pelos professores nos permite reafirmar a ideia de que a pesquisaação colaborativa é a terminologia que melhor descreve e situa o processo de trabalho vivenciado pelos professores desta rede de ensino.

\section{SOBRE A ANÁLISE DOS REGISTROS PRODUZIDOS}

Das experiências que brotaram das quatro escolas da Rede Municipal de Ensino de Porto Alegre (RME/POA), vividas de diferentes formas e modos, várias alternativas foram criadas para realizar a prática educativa em cada uma delas, procurando observar e respeitar os limites e potencialidades locais. Foram os relatos dessas experiências que serviram de suporte para a reflexão aqui empreendida. Para melhor situar o leitor, fazemos uma breve descrição das características de cada uma das escolas em que atuam os professores autores dos textos analisados.

A Escola Municipal de Ensino Fundamental Professor Gilberto Jorge Gonçalves da Silva, pioneira do movimento de construção da Docência Compartilhada, apresenta diferentes lugares e modos do exercício docente, dado por meio das múltiplas vozes de seus professores que se anunciam e contam sobre o que significa ser e estar professor numa relação de parceria. Nos textos dos profissionais dessa escola há uma rica descrição dos caminhos percorridos para a elaboração do projeto de Docência Compartilhada. A experiência que os professores vivem em seu cotidiano carrega como marca a interdisciplinaridade, revelada pela ação de cada um no movimento intenso de construir parcerias que permitam recriar as práticas em sala de aula e nos espaços da gestão escolar, o que revela a ação coletiva instalada no interior da escola.

$\mathrm{Na}$ Escola Municipal de Ensino Fundamental Vereador Martim Aranha, um projeto comum desencadeado por um pequeno grupo de professores ganhou dimensão coletiva e foi traduzido como Projeto Composições. Tem por base, igualmente, a ideia do compartilhamento da docência na educação básica. A proposta do Projeto Composições vem se instalando na comunidade educativa e, paulatinamente, ganhando espaço e adesões, tanto dos docentes e gestores, quanto dos estudantes. Os registros revelam, traduzem e explicitam as intenções que originaram o trabalho, os percursos e percalços da trajetória vivenciada ao programar sua proposta. 
A experiência realizada na Escola Municipal de Ensino Fundamental Dolores Alcaraz Caldas anuncia a necessária sistematização de pressupostos teóricos e princípios pedagógicos como elos estruturantes e importantes para o desenvolvimento do trabalho de inclusão na escola. Ao contar o percurso para chegar ao projeto ali desenvolvido, os autores descrevem um conjunto de aprendizagens que foram construídas ao longo do processo. Indicam, de igual maneira, o quanto há de desafios que anunciam o exercício da docência compartilhada como uma permanente reconfiguração da prática docente na e da escola.

A Escola Municipal de Ensino Fundamental Vila Monte Cristo envolveu-se mais tardiamente no projeto e, por isso, seu relato tornou-se um texto rico na medida em que permite a cada um a possibilidade de olhar com apreço e atenção para aquelas iniciativas que ainda se encontram em sua fase de germinação. De algum modo, é costume no campo educativo ancorar as reflexões em práticas que já tenham ganhado expressão e visibilidade. Por isso, a singeleza do relato tecido por seus professores está justamente no anúncio de que nada existe sem que antes tenha sido embrionário em sua constituição. O que, por si só, já anuncia, também, o necessário processo de lançar-se na construção de percursos que permitam ampliar e manter as inovações para que, assim, efetivamente, possamos demarcá-las como evidências de mudanças e transformações.

Nas quatro comunidades educativas, de formas diferenciadas, tanto no que diz respeito aos tempos e espaços, quanto na forma com que foram elaboradas, as práticas transformadas em narrativas permitem a socialização da experiência de docência compartilhada. Quando escrevemos sobre o que fazemos e somos, nós ampliamos as possibilidades interpretativas e ativas em nossas instituições. Os professores se lançaram ao movimento de reinventar seu exercício docente e também se dispuseram ao exercício da compartilha da ação docente mediante a prática da escrita.

A seguir, socializamos algumas considerações que a leitura dos textos escritos pelos professores e o próprio processo de composição dos mesmos suscitaram. Três pontos são demarcados em função de seu caráter inovador e anunciador de outras formas de pensar e fazer a docência na Educação Básica. Eles servem também como elementos avaliativos da construção de projetos diferenciados na escola básica. São eles:

a) a prática da Inclusão desde a experiência cotidiana da docência;

b) a formação de professores desde a dimensão da pesquisa e da autoria escrita; 
c) a compreensão de Docência Compartilhada e de trabalho coletivo na escola.

Amparados nas histórias, práticas e projetos sistematizados pelos professores-pesquisadores, faremos uma ampliação da reflexão buscando indicar argumentos e elementos que permitam constituir e/ou apontar pressupostos para o trabalho de gestão da educação pública. Cabe destacar que a exigência em trabalhar os efeitos de uma ação, que se pretende inovadora no campo da educação básica, deve também ser contemplada no âmbito da construção dos projetos e matrizes curriculares que sustentam a formação de professores.

\section{a) A prática da Inclusão desde a experiência cotidiana da docência}

Pode-se anunciar com certa segurança que os relatos revelam ações que emergiram do cotidiano do fazer educativo. Resultam de movimentos autênticos que, acima de tudo, trazem a preocupação e o compromisso com a construção de formas alternativas da ação educativa e de gestão democrática dos processos de ensino que rompam com a forma fragmentada, linear e individualizada de organização e realização da docência e, consequentemente, das práticas educativas escolares:

Nos reconhecemos gestores de uma escola que ainda funciona em tempos marcados pelo relógio e ligados ao conceito de hora/aula; ainda temos professores referência e especializados, que, apesar do desejo e investimento deles e da escola, seguem trabalhando de forma desarticulada e individualizada; e que também, ainda, se move pela lógica dos conteúdos mínimos a serem abordados e, com sorte, assimilados. ${ }^{5}$

A preocupação com a diferença, emanada da diversidade cultural e social, inerente à constituição histórica da sociedade brasileira, assim como a presença cada vez maior de alunos com deficiência configuram-se como pontos em comum entre os textos produzidos. É a preocupação com a diferença que gerou em cada uma das escolas a construção de alternativas educativas à inclusão. Podemos verificar esse aspecto no registro de um grupo de professoras:

Resumidamente, podemos dizer que o Projeto de Docência Compartilhada tem sua origem nos seguintes fatores:

a) aumento do número de alunos com diversas deficiências na escola em um breve período de tempo; 
b) maior número de jovens com alguma deficiência, em processo de alfabetização, chegando ao III Ciclo;

C) muitos alunos permanecendo por mais de dois anos em Turma de Progressão (TP);

Tudo isso estava gerando uma configuração de turmas de progressão homogênea - ainda que a diversidade estivesse presente -, dificultando o estabelecimento de conflito cognitivo favorável à aprendizagem. Essa realidade andava na contramão dos princípios da escola. ${ }^{6}$

Quando os professores das escolas colocam em movimento propostas de trabalho que extrapolam o fazer individual, modo clássico da atuação docente, assumindo como pressuposto a colaboração, a partilha, o permitir que o outro (colega) atravesse sua ação profissional, não só aspectos didático-pedagógicos, visando o bem comum do aluno estão em cheque, mas também novos modos de constituir-se como educador e como profissional da educação são vislumbrados e tecidos. Ou seja, os professores assumem o processo de enunciação dos fazeres educativos que visibilizam ações provenientes da diversidade e, consequentemente, essa ação acaba desencadeando outras parcerias necessárias no interior da dinâmica escolar. Surgem articulações com outros espaços de aprendizagem como o Laboratório de Aprendizagem e a Biblioteca assim como a criação de projetos oriundos de iniciativas individuais. Na verdade, é possível observar que a busca por parceria no trabalho docente acaba possibilitando a criação de um outro dinamismo, diferenciado do trabalho convencional para o qual o educador foi formado.

Tal movimento localizado pode ser inserido nas discussões que vêm paulatinamente ganhando espaço no campo da formação continuada de professores. Nunes (2001) informa que, ao resgatar a prática dos educadores como elemento fundamental para se repensar a formação continuada, os estudos acabam por evidenciar "o professor em sua própria formação, num processo de autoformação, de reelaboração dos saberes iniciais em confronto com sua prática vivenciada" (p. 30). Nesse movimento, a busca por outros modos de viver a educação instala-se no cotidiano educativo da comunidade escolar, provocando a construção de outras redes que ganham o espaço interno da escola, sem, entretanto, limitar-se a ele. Esses outros modos de viver a educação vão "invadindo", também, o universo da comunidade educativa da rede de ensino, abrindo-se para a constituição de uma dinâmica em que escolas com projetos semelhantes buscam, pela parceria, apoiar-se e partilhar suas ações. 


\section{b) Formação de professores desde a dimensão da pesquisa e da autoria escrita}

Os investimentos da pesquisa sobre os processos de formação de professores têm uma ampla trajetória e riqueza de temáticas que conformam os estudos nesse campo. Pesquisadores e professores têm investido na pesquisa, preocupados com os desafios que envolvem os processos de ensino e aprendizagem. Buscam ações formativas que possibilitem tornar os professores capazes de responder efetivamente à complexidade que marca a sociedade contemporânea. Quando os desafios postos se complexificam, como o é no caso da inclusão, necessário se faz o movimento de pensar os processos de formação continuada nos tempos e espaços da educação básica.

Os processos de formação inicial de professores vêm considerando essa diversidade e riqueza de abordagens sobre a temática da inclusão. Entretanto, constata-se que a descrição e apresentação de práticas inovadoras ainda são insipientes para os processos de acompanhamento da atuação dos professores em formação, principalmente quando realizam suas práticas de estágio ou estão no início da sua atividade docente. Já na organização dos processos de formação continuada, várias ações vêm sendo construídas de forma mais sistemática.

Nesse contexto, a formação continuada ganha ênfase por meio da pesquisa, da reflexão e do exercício da autoria que se faz mediante a escrita. Fazendo uso desses três processos, enquanto recursos metodológicos, criam-se possibilidades interpretativas e de ação que permitem aos professores o desenvolvimento de sua capacidade de debruçar-se sobre aquelas situações do cotidiano que deles requerem uma maior dedicação e envolvimento na reconstrução de práticas, estratégias e intervenção junto às crianças, principalmente aquelas marcadas por algum tipo de dificuldade ou deficiência. Assim descreve um grupo de educadores pesquisadores:

Entre as aprendizagens, destacamos: a atenção às pedagogias que desenvolvemos; a necessidade de problematizar o currículo escolar e o trabalho com a diferença na escola; a disposição para trabalhar, apoiando-se em um terreno menos seguro, mais incerto, provisoriamente escolhido, permanentemente problematizado. Precisamos nos indagar sobre as normas fixadas, os conhecimentos eleitos, os métodos utilizados. Quem está incluído? Quem estamos deixando de fora? Esses são limites, possibilidades e desafios que se colocam quando nos propomos a discutir e problematizar a inclusão das diferenças na escola regular. ${ }^{7}$ 
O esforço de escrita realizado pelos professores mostra o quanto a tarefa educativa desenvolvida na escola cada vez mais é potencializada mediante a compreensão de que o professor ocupa um lugar central como aquele que organiza, orienta e acompanha, sistematicamente, crianças e jovens em seu processo de construção do conhecimento. Nessa perspectiva, exige-se que o professor seja um pesquisador de sua ação, ou seja, um professor-pesquisador. Ser um professor-pesquisador significa ser um professor-leitor que se joga no movimento de interpretar e escrever o que vê e como vê, o que está ao seu redor e em si mesmo como alguém que se faz no exercício de compartilhar a docência.

O exercício de escrita realizado permitiu aos professores ampliar a competência de analisar as questões do cotidiano da docência compartilhada, tornando-os mais sábios para redefinir e recriar suas estratégias de ação. Ao realizar o exercício de leitura e de escrita do que cada professor vem fazendo no interior de suas escolas, na instigante tarefa de trabalhar colaborativamente, é possível indicar que há, ao modo de cada um e de cada escola, uma ampliação do repertório de ideias e ações. Tal movimento também oferece elementos para que os professores se tornem mais seguros no seu agir e no seu envolvimento na criação de novas políticas e práticas de educação no campo da inclusão.

c) A compreensão de Docência Compartilhada e de trabalho coletivo na escola

Em todos os registros, a composição da docência compartilhada, entre dois ou mais professores, tem sido uma alternativa positiva às turmas que representam um maior desafio para a escola, no âmbito da aprendizagem para todos. O modelo de bidocência utilizado na cidade de Hamburgo, Alemanha, apresentado por Beyer (2005), autor referido em alguns dos registros produzidos, pode ser identificado como inspirador para os projetos que estão sendo desenvolvidos nas quatro escolas. Segundo o autor, essa experiência se faz presente em contextos onde há a presença significativa de alunos com deficiência, preferencialmente, com um professor com formação em Educação Especial, objetivando a individualização do ensino para tais alunos.

As experiências de docência compartilhada que estão ocorrendo nas salas de aula das quatro escolas já referidas parecem ampliar o sentido da bidocência referida por Beyer. Um dos sentidos transparece nos escritos sobre as vivências dos professores das quatro escolas entre si, ou seja, no exercício de planejar e agir juntos, em sala de aula. São alternâncias nos movimentos de poder da relação de docência da sala de aula marcados 
pelo fortalecimento das ações didático-pedagógicas e por uma maior oportunidade de interlocuções. E esses são aspectos que ampliam o sentido da bidocência. Não se trata mais de dois professores de áreas distintas e com focos distintos, mas de dois professores de áreas distintas que atuam de modo compartilhado. E, nesse exercício de compartilha, necessário se faz lidar com inseguranças e buscar entender e constituir uma ação em parceria, de corresponsabilidade e colaboração ativa, principalmente na construção das estratégias didáticas e de intervenção educativa.

Devido à concepção que se tem tido até agora do que seja dar aulas, é muito provável que um professor, ao iniciar um trabalho de docência compartilhada, sinta-se inseguro. Nós identificamos dois motivos. O primeiro relaciona-se ao fato de ter que dividir o espaço de professor com outros colegas. $O$ segundo refere-se à tarefa de lidar com alunos que apresentem alguma deficiência. Não pensem que conosco foi diferente. Foi exatamente isso o que aconteceu. Nós tivemos medo. No entanto, as alianças feitas, na verdade, criaram um resultado tão positivo, que logo o professor passa a sentir medo de ter que trabalhar sozinho e não se sentir desafiado a trabalhar com aquela criança que não é exatamente o modelo de aluno que existe no imaginário de muitos educadores. ${ }^{8}$

Os professores descrevem pequenas mudanças individuais provocadas durante o processo, tais como: aprender a olhar, ouvir e conversar sobre o que fazer e como agir, juntos, em sala de aula, afirmando a potência criadora que está no necessário processo de desconstrução e construção das relações de docência. Parece ter sido no processo da escrita que uma maior consciência sobre a riqueza da ação coletiva tornou-se mais evidente aos próprios professores envolvidos:

Os encontros para escrita nunca reuniram a totalidade do grupo docente, mas a riqueza de cada desses encontros permitiu, não apenas o registro desse momento e movimento histórico que estamos vivendo, mas aproximou-nos e repercutiu ricamente num outro patamar de "composição" (Projeto Composições) e de "partilha"(Docência Compartilhada), desvelando que sempre há um passo a mais a ser dado; nesse caso específico saímos de encontros voltados para o planejamento e replanejamento, pois compusemos e partilhamos a escrita e publicação de uma história que estamos pretendendo construir. ${ }^{9}$

Outro aspecto refere-se ao trabalho coletivo na escola. O trabalhar coletivamente, nos contextos aqui referidos, ganha diferentes formas e expressões: ora marcadas pelo universo da escola como um todo; ora pelos agrupamentos que surgem no interior da escola. Conforme bem explicitam os educadores, "a reunião entre os professores do Projeto Composições 
garantiria trocas de percepções sobre o grupo, o planejamento de estratégias de intervenção e preparação de materiais, que são aspectos essenciais para a efetivação da docência compartilhada e cooperativa".10

A alusão aos problemas e dificuldades de atuar em parceria na sala de aula, manifestados pela estranheza à presença do outro, também podem ser entendidos como manifestação de que a individualidade da ação docente precisa ser preservada quando buscamos formas colaborativas de trabalho na escola. Fullan e Hargreaves (2000, p. 62) advertem que, quando buscamos a eliminação do individualismo, não podemos erradicar com ele a individualidade, pois ela é quem dá origem à discordância criativa e ao risco, fontes da aprendizagem grupal dinâmica.

A experiência da docência compartilhada vivida de diferentes formas nas quatro escolas mostra que é possível trabalhar de forma coletiva. É possível inferir que pequenos movimentos de trabalho coletivo são tecidos à medida que os confrontos, as justaposições e o compartilhamento de ideias também são feitos. Tais formatos podem ser indicativos de novas possibilidades de organização do trabalho colaborativo.

\section{A títULO DE FINALIZAÇÃO}

Os textos das professoras transcrevem valorosas experiências de aprendizagem, de reflexão e, sobretudo, de inserção no contexto de "acontecência" do projeto Docência Compartilhada. Através dos textos produzidos pelos professores, todos ancorados em práticas pedagógicas de gestão da escola ou da sala de aula, a problemática da diferença ou, de outra forma, daquilo que vem se convencionando chamar de Educação Inclusiva, foi abordada em sua complexidade.

Os textos apresentaram diferentes possibilidades de organização e execução dos projetos de Docência Compartilhada. A demarcação dessas diversas formas, feitas em diferentes turmas, sem dúvida, aponta para o caminho de uma inovação pedagógica. É fácil compreender que, por razões ímpares, cada um desses espaços escolares se viu pressionado e convocado a, de alguma forma, tentar dar conta dos inúmeros desafios que se colocam à escola da contemporaneidade com a inclusão, cada vez maior, de todos na escola.

Nos últimos tempos, a parcela desse todos que mais tem desestabilizado a escola é composta, tanto por aqueles que estavam do lado de fora - os fracassados, miseráveis, doentes, loucos, da rua, sem família - quanto por aquela parcela de crianças e jovens que estão na escola, mas, para os quais, ela não faz o menor sentido como instituição de socialização do conhecimento. 
Tal distinção parece estar presente na construção das reflexões feitas pelos professores na medida em que passam a ver a criança ou jovem que ali está para além de uma condição social, biológica ou escolar a ela imputada em determinado momento. $O$ exercício de escrita sobre o que se tem feito parece indicar subliminarmente que outras lógicas de entendimento do que é a infância e a juventude estão emergindo.

Percebemos que os projetos construídos nas escolas surgiram da inquietude em face do problema de viabilizar uma escola de qualidade para todos. Exemplo disso é a alternativa construída em uma das escolas para repensar o processo de acompanhamento das aprendizagens dos alunos:

A avaliação do aluno ocorreria em todos os momentos, tanto nas produções individuais e coletivas, quanto na sistematização dos projetos de trabalho. Todos os elementos relativos aos avanços e necessidades dos alunos seriam destacados para compor o portfólio da trajetória desse aluno. ${ }^{11}$

Diferentes linguagens, como a música, as artes plásticas, o teatro, o artesanato, o cinema, a fotografia, a dança são colocadas à disposição dos alunos para que, juntos com seus professores, consigam achar novos caminhos para se expressar e, assim, produzir conhecimento. Talvez as diferentes linguagens sejam até alternativas, em um primeiro momento, à linguagem escrita, já tão carregada de desapontamentos no território escolar.

Tudo isso implica verdadeiras revoluções no campo da escola. Há que se desacomodar tempos, espaços, gerenciamentos de projetos pedagógicos, estudos, tutelas e afetos. É muito para a escola moderna que sempre esteve alicerçada no ideal da homogeneização! Percebe-se nas ideias organizadas que há o desejo e a potência de transformação, diferentemente de se fazer mais uma reforma ou mudança de nomenclatura no velho trabalho de sempre.

A preocupação em desenvolver outra lógica para o trabalho com os alunos nessas escolas deixa clara a intenção de protagonizar o desafio da educação inclusiva. Para tal, os professores das escolas envolvidas com o projeto Docência Compartilhada pesquisaram, problematizaram a realidade da escola, buscaram parcerias, socializaram informações, submeteram seus projetos à mantenedora. $\mathrm{E}$, cada uma das escolas, movidas por elementos diferentes entre si, mas tendo como ponto comum a problemática da educação inclusiva de qualidade para todos, foi construindo sua trajetória de organização e gestão das práticas de docência.

Da experiência de acompanhar esse processo de formação e de escrita colaborativa, como pesquisadores da Universidade, sintetizamos alguns aprendizados: 
a) O estabelecimento de parcerias com instituições de ensino superior (centros de pesquisa, grupos de pesquisa e ou pesquisadores especializados no trabalho de formação de professores) demonstra, preliminarmente, uma mútua aprendizagem entre universidade e escola. Não somente professores da educação básica qualificam suas experiências, mas também, pesquisadores aprendem como construir ferramentas mais apropriadas para trabalhar analiticamente com o fenômeno educativo cotidiano, qualificando os processos de formação inicial de professores.

b) Inclusão, diferença e diversidade são elementos preponderantes no cotidiano atual das ações educativas das quatro escolas que, potencializados pelo estímulo do trabalho compartilhado, geram outros modos de organização da estrutura curricular, o que exige manter a criação permanente de dinâmicas de gestão dos processos escolares.

c) A formação de professores, desde a dimensão da pesquisa e da autoria escrita, permite a travessia do lugar de quem faz e assiste para o lugar de protagonistas do próprio fazer e pensar. Desse modo, os docentes anunciam-se como autores num duplo sentido. O primeiro, da ação pragmática rotineira; o segundo, do ato de pensar sobre o que se faz. Como resultado desse processo, o registro sistematizado pelos professores revelouse com potencial analítico e de autocrítica.

d) A compreensão de Docência Compartilhada e de trabalho coletivo na escola manifesta a angústia de abrir-se ao outro (colega docente) no seu fazer profissional, através do compartilhamento, não só de projetos pontuais, mas do próprio espaço físico em sala de aula e do exercício efetivo da docência. Em muitos casos, marcados inicialmente pelo receio, dá-se lugar à parceria e ao desenredamento dos (des)afetos em prol de um projeto maior, o trabalho coletivo e a aprendizagem de todos.

e) A organização e a gestão de práticas diferenciadas, criativas e criadoras de aprendizagem em sala de aula acontecem porque a diferença força o processo de acesso às novas linguagens. Tal processo induz a escola a reconhecer outras formas de linguagens como organizadoras do conhecimento e a experimentar a lógica da estética em seus contextos majoritariamente marcados pela lógica da racionalidade científica.

f) A criação de espaços em rede maximiza os esforços empreendidos pelos educadores no cotidiano, assim como o estabelecimento de interfaces com as instituições e centros de pesquisa, permitindo rever o que se faz na educação básica por dentro do próprio fazer. Essa dinâmica possibilita que os processos rotineiros da educação básica ganhem outros aportes para além 
do fazer, ou seja, pensar e divulgar o que se faz. Nesse sentido, um dos papéis que podem ocupar os assessores de redes públicas de ensino, responsáveis por criar políticas de formação continuada para educação básica, é a assunção do lugar de mediadores entre a comunidade educativa e outras agências de formação, como a Universidade, ampliando o alcance das experiências para além do local em que são produzidas.

Por fim, cabe ressaltar que o envolvimento dos professores na construção de projetos de inclusão revelou sua vontade de enfrentar o imobilismo e os processos de exclusão que se estabelecem quando a diferença emerge na escola. Os escritos revelaram preocupações, tanto dos professores quanto de suas coordenações pedagógicas, com a organização de um currículo que remeta a aprendizagens significativas, centrado em vivências de cidadania e que privilegiem a participação, o saber fazer escolhas e o dialogar com as diferenças.

\section{FORMATIVE PROCESSES ARISING FROM INCLUSIVE PRACTICES IN BASIC EDUCATION}

ABSTRACT: This article is the result of a research experience, of a collaborative nature, carried out with a group of teachers from four schools in Porto Alegre's municipal school network. The genesis of the research process established between the University and the School and the progress of formation meetings and collaborative writing are analyzed. From the theoretical-methodological contributions of action research, a process of ongoing education and collaborative writing is systematized and evaluated. Out of an analysis of the written records of teachers, three aspects can be highlighted, which have the innovative character of the ways of thinking and teaching in basic education: a) the practice of inclusion from the everyday experience of shared teaching; b) formation of teachers from the perspective of research and written authorship; and, c) the understanding of Shared Teaching and collective work in the school as indicators of educational innovation. Finally, it is argued that the movement of ongoing formation, when conducted in a network, leads to improvements in teaching practice and in the qualification of procedures for educational inclusion.

KEYWORDS: Teacher formation. Inclusive education. Action Research. Shared teaching. Collaborative writing.

\section{NOTAS}

1. Trataremos sobre essa perspectiva de pesquisa mais adiante, neste trabalho.

2. A etapa de construção do projeto de pesquisa ocorreu durante o segundo semestre de 2007. As atividades de formação, de pesquisa e de escrita colaborativa foram realizadas ao longo do ano de 2008. 
3. A partir deste momento passamos a utilizar a ideia de grupo de pesquisadores, abarcando tanto os professores da instituição de ensino superior quanto os professores da educação básica envolvidos nos projetos em andamento em cada uma das comunidades educativas da rede municipal de Porto Alegre. O total de professores envolvidos no projeto de pesquisa foi de quarenta e um (41), sendo quinze (15) da Escola Gilberto Jorge, dezessete (17) da escola Vereador Martin Aranha, dois (2) da escola Monte Cristo e sete (7) da Escola Dolores Alcaraz Gomes. Os nomes das escolas que desenvolvem o projeto "Docência Compartilhada" são reais e estão sendo utilizados com sua autorização.

4. O conjunto dos textos foi compilado em uma obra denominada Docência compartilhada: educação em tempos e espaços de inclusão, que se encontra em fase de editoração para publicação.

5. Registro intitulado: "Cursos e percursos do Serviço de Orientação Pedagógica (SOP) junto ao projeto Composições", elaborado por Denise Almeida, Maria Salete Roman Ross, Patrícia Andrades Oliveira, Sandra Jaqueline Salvador dos Santos. 2008.

6. Registro intitulado "Docência Compartilhada: Uma alternativa para novos desafios a uma escola para todos", elaborado por Ana Elisabete Krieger Lopes Reis, Márcia Dias Loguércio, Márcia Elaine Terra Soares, Maria Madalena Ferrari, Maria Rosângela Carrasco Monteiro, Mariza Rabello de Almeida e Suzana Moreira Pacheco. 2008.

7. Registro intitulado:"Da turma de progressão à docência compartilhada: uma experiência de inclusão na Escola Municipal de Ensino Fundamental Dolores Alcaraz Caldas", elaborado por Maria Cláudia Dal'Igna, Paula Cristina Pagot, Elenilton Neukamp, Ester Rodrigues Leão, Priscila Gomes Dornelles, Denise Severo Spadoni de Vargas, Catiana Quadros da Silva Pessi. 2008.

8. Registro intitulado: "Compartilhando a docência. Por um novo olhar na Inclusão Escolar", elaborado por: Adriana Longoni Moreira, Ana Maria Oliveira Morales, Eliane Herzog Pellegrini Viana, Rosa Maria Gruppelli Adamoli. 2008.

9. Registro intitulado:"Projeto Composições: construindo pontes para novos tempos e espaços escolares", elaborado por Aline Araújo da Silva, Cristiane Souza Goulart, Denise Nolibos de Almeida, Denise Rodrigues Nunes Neves, Graciela KraKhecker, lara Stein Lacchini, Lúcia Regina Possebon Martins, Magda Liane Lisboa Xavier, Márcia Almeida Soares, Maria Salete Roman Ross, Patrícia Oliveira Andrade, Sandra Jaqueline Salvador dos Santos, Thereza Cristina Rodrigues. 2008.

10. Idem.

11. Ibidem. 


\section{REFERÊNCIAS}

ABDALLA, M. de F. B. A pesquisa-ação como alternativa para análise da prática docente. 27a Reunião anual da Anped, Caxambu, 2004. Disponível em: <www.anped.org.br> GT n. 4 - Didática.

BEYER. H. O. Inclusão e avaliação na escola. De alunos com necessidade educacionais especiais. Porto Alegre: Mediação, 2005.

CANÁRIO, R. A escola tem futuro? Das promessas às incertezas. Porto Alegre: Artmed, 2006.

ENGEL, G. I. Pesquisa-ação. Educar, n. 16, Curitiba, p. 181-191, 2000.

FRANCO, M. A. S. Pedagogia da pesquisa-ação. Educação e Pesquisa, v. 31, n. 3, p. 483502, dez. 2005.

FULLAN, M.; HARGREAVES, A. A escola como organização aprendente. Buscando uma educação de qualidade. 2. ed. Porto Alegre: Artmed, 2000.

GRIGOLI, J. A. G. et al. A formação do professor investigador na escola e as possibilidades da pesquisa colaborativa: um retrato sem retoques. Revista Lusófona de Educação, n. 10, p. 81-95, 2007.

MIRANDA, M. G. de; RESENDE, A. C. A. Sobre a pesquisa-ação na educação e as armadilhas do praticismo. Revista Brasileira de Educação, v. 11, n. 33, p. 511-518, dez. 2006.

MONCEAU, G. Transformar as práticas para conhecê-las: pesquisa-ação e profissionalização docente. Educação e Pesquisa, v. 31, n. 3, p. 467-482, dez. 2005.

NUNES. C. M. F. Saberes docentes e formação de professores: um breve panorama da pesquisa. Educação \& Sociedade, ano XXII, n. 74, p. 27-42, abr. 2001.

PACHECO, S. M. Plano de Trabalho Projeto Composições/Docências Diferenciadas. Porto Alegre: PMPA/SMED, 2008. (Digitado).

PACHECO, S.; MONTEIRO. M. R. Proposta de trabalho "Docência Compartilhada". Porto Alegre, 2007. 4 p. (Digitado).

PAULON, S. M.. A análise de implicação com ferramenta na pesquisa-intervenção. Psicologia e Sociedade, v. 17, n. 3, p. 18-25, dez. 2005.

PERSCH, M. I.; PACHECO, S. M.; MONTEIRO, M. R. (Org.). Uma escola para todos, uma escola para cada um. Porto Alegre: Prefeitura Municipal de Porto Alegre, Secretaria Municipal de Educação, 2006.

PIMENTA, S. G. Pesquisa-ação crítico-colaborativa: construindo seu significado a partir de experiências com a formação docente. Educação e Pesquisa, v. 31, n. 3, p. 521-539, 2005.

SILVA, G. F. da; SOUSA, D. H. Percursos singulares na construção de ações coletivas: diferentes modos de conversações entre professores. In: SOUSA, D. H. et al. Conexões 
educativas. Ensinar e aprender para além do que se vê. Porto Alegre: Prefeitura Municipal de Porto Alegre/Secretaria Municipal de Educação, 2006. p. 173-182, v. I.

TARDIF, M.; RAYMOND, D. Saberes, tempo e aprendizagem do trabalho no magistério. Educação e Sociedade, v. 21, n. 73, p. 209-244, 2000.

ZEICHNER, K. M.; DINIZ-PEREIRA, J. E. Pesquisa dos educadores e formação docente voltada para a transformação social. Cadernos de Pesquisa, v. 35, n. 125, p. 63-80, maio 2005.

GILberto FerReIRA DA Silva: Pós-doutor em Educação pela Universidade de Barcelona, doutor em Educação pela Universidade Federal do Rio Grande do Sul. Atua no Curso de Mestrado em Educação e no curso de Pedagogia do Unilasalle. Pesquisador CNPq.

E-mail: silberto.ferreira65@gmail.com ou ferreira@unilasalle.edu.br

MARTA NörnBerg: Doutora em Educação Pela Universidade Federal do Rio Grande do Sul. Professora do Curso de Pedagogia do Unilasalle.

E-mail: martaze@terra.com.br

SuzANa MoreiRa PACHECO: Doutoranda em Educação pela Universidade Federal do Rio Grande do Sul, professora da Rede Municipal de Ensino de Porto Alegre.

E-mail: suzpacheco@unilasalle.edu.br 